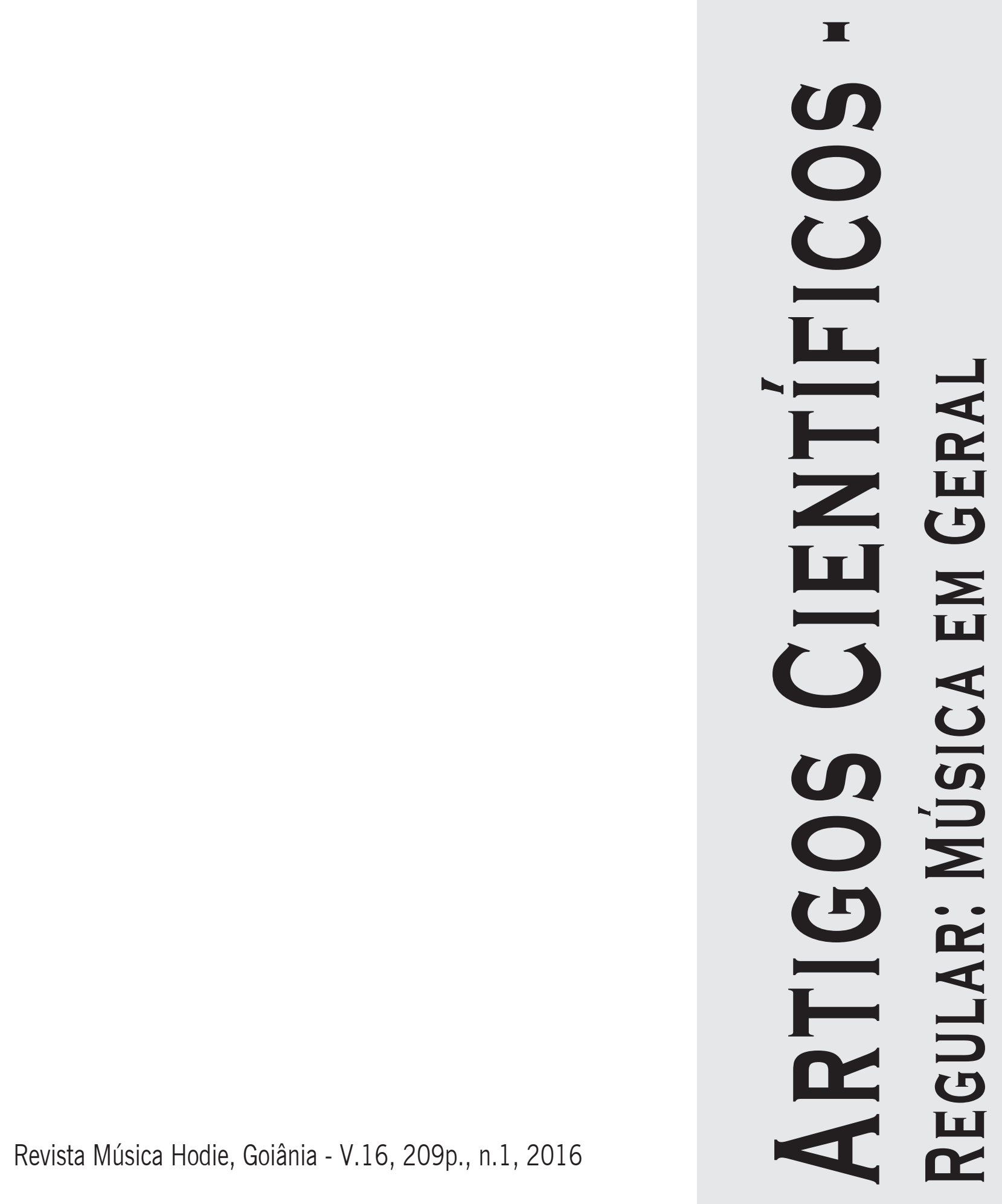




\title{
Estilo segundo um gosto nacional: os estilos italiano e francês como modelos e juízes do bom gosto da música setecentista
}

\author{
Noara Paoliello (CMU-ECA/Universidade de São Paulo, São Paulo, SP, Brasil) \\ noarapaoliello@gmail.com
}

\begin{abstract}
Resumo: Este artigo investiga as principais discussões setecentistas sobre estilos nacionais e formação do bom gosto na música a fim de compreender questões centrais para a prática musical conhecida atualmente como historicamente orientada. Para tanto, utiliza-se como referencial teórico fontes primárias do séc. XVIII assim como fontes secundárias que resgatam questões relativas ao estilo musical setecentista. É notável nas obras de autores como Mattheson (1713) e Quantz (1752) a preocupação com a formação do gosto musical - ainda que essas obras fossem tratados de música prática. Através dos textos de época, conclui-se que os conhecimentos do músico de bom gosto iam muito além das habilidades técnicas, sendo o entendimento das características de cada estilo nacional uma das habilidades fundamentais - seja no tocar ou no compor.
\end{abstract}

Palavras-chave: Estilo Musical; Formação do Gosto musical; Gosto Nacional; Música Setecentista.

Style according to national taste: italian and french styles as models and judges of good taste in eighteenth century music

Abstract: This article investigates the main discussions about national styles and the formation of good taste in music in order to understand central issues to the musical practice known today as historically oriented. The theoretical references used are primary sources of eighteenth-century as well as secondary sources that rescue issues related to eighteenth-century musical style. It is remarkable in the works of writers such as Mattheson (1713) and Quantz (1752) the concern with the formation of musical taste - although these works were treaties about practical music. Through texts from the period, it is concluded that the knowledge of the musician with good taste went far beyond technical expertise, and the understanding of the characteristics of each national style was one of the fundamental skills - whether in playing or composing.

Keywords: Musical Style; Formation of Musical Taste; National Taste; Eighteenth-Century Music

Estilo según un gusto nacional: estilos italiano y francés como modelos y jueces del buen gusto de la música sietecientista

Resumen: Este artículo investiga las principales discusiones sobre estilos nacionales y formación del buen gusto en la música para comprender las cuestiones centrales de la práctica musical conocido hoy en día como históricamente orientada. Por lo tanto, se utiliza como referencial teórico fuentes primarias de del siglo. XVIII, así como fuentes secundarias que se ocupan de cuestiones relacionadas con el estilo musical del siglo XVIII. Es notable en las obras de autores como Matthenson (1713) e Quantz (1752) la preocupación con la formación del gusto musical - aunque estas obras fuesen tratados de música práctica. Através de los textos de época se concluye que los conocimientos del músico de buen gusto iban más allá de las habilidades técnicas, siendo el entendimiento de las características de cada estilo nacional una de las habilidades fundamentales - sea en el tocar o en el componer.

Palabras clave: Estilo Musical; Formación del Gusto Musical; Gusto Nacional; Música Sietecientista

O importante tratado de Johann Joachim Quantz traz no título da $1^{\mathrm{a}}$ edição (1752) as seguintes palavras: "Ensaio de um Método para se Tocar a Flauta Transversal, acompanhado de observações úteis para promover o Bom Gosto na música prática, explicado com exemplos". ${ }^{1}$ No prefácio da obra, Quantz ressalta a importância de se treinar a inteligência do músico, e não apenas a parte técnica, formando o gosto e estimulando o discernimento.

A grande preocupação com o gosto no contexto musical setecentista estava relacionada com a formação do bom gosto, que se dava através do estudo e exercício dos modelos corretos (PAOLIELLO, 2011. p. 25). Assim, em sintonia com a tendência do século das luzes, teóricos e compositores alemães dedicaram seus tratados ao aperfeiçoamento racional e refinamento do gosto mesmo quando estavam tratando de uma música prática, mostrando que os conhecimentos do músico (de bom gosto) iam muito além das habilidades técnicas. 
Para tanto, o entendimento dos diferentes estilos musicais figurava entre os conhecimentos fundamentais a serem adquiridos pelo músico. Quantz escreve:

Para julgar adequadamente a composição e a performance musical como um todo (...) é necessário, além de ter um perfeito bom gosto e um entendimento das regras de composição, possuir discernimento suficiente sobre o estilo e característica de cada peça, seja ela composta segundo o gosto desta ou daquela nação, para essa ou aquela finalidade, e ter discernimento para que não se confunda uma coisa com outra. ${ }^{2}$ (QUANTZ, 1983, p. 287)

Autores setecentistas destacam dois gostos nacionais principais - o italiano e o francês - amplamente imitados pelas demais nações europeias, especialmente pelos alemães. A França representava tudo o que era almejável em termos de uma nação unificada e fornecia as maneiras da corte, exportando, em consequência, sua música - principalmente a música teatral de dança e as ouvertures. A Itália, referência para diversos tipos de arte, proveu o modelo de ópera e de diversos gêneros instrumentais. Com base em críticas e discussões setecentistas sobre os dois principais estilos musicais em voga nos sécs. XVII e XVIII, o presente artigo investiga questões relevantes para a prática musical conhecida atualmente como historicamente orientada.

\section{Estilo segundo o gosto nacional}

A extensa tratadística sobre os preceitos do gosto, que circulou na Europa nos sécs. XVII e XVIII, refere-se ao termo como uma faculdade sensorial - porém racional - responsável pelo julgamento das sensações provocadas pela obra de arte no espectador. Assim, o gosto regulava a crítica da arte no séc. XVIII, com sua faculdade de julgar seus atributos, como o Belo, o Bom, o Agradável, o Sublime. Ainda, as definições setecentistas sobre gosto estabelecem relação com as maneiras e estilos característicos de uma época, país e auctoritas, sendo o gosto nacional determinante das maneiras de compor e regulador dos estilos próprios de um determinado grupo. (PAOLIELLO, 2011. p. 21)

Assim, o gosto nacional diz respeito à perpetuação de determinadas características nas obras dos autores de um mesmo país. O gosto, com seu poder de discernir, qualificar e eleger, ajuda a estabelecer uma maneira de compor, de tocar e de ouvir. Com base nessas ideias, podemos dizer que o gosto, consistindo no juízo, na escolha e na aprovação de algo, acabará por moldar e definir uma maneira de compor - pessoal ou de um grupo.

Umberto Eco, escrevendo sobre a beleza na estética medieval, faz uma referência ao gosto nacional já no séc. XIII, onde o gosto possui certa relatividade "conforme os diferentes tempos e países, pelo qual todo aspecto visível realiza um tipo de convenientia que, todavia, não é nunca o mesmo, porque, assim como variam os hábitos, cada um tem seu próprio senso estético”. (ECO, 2010, p. 163-164)

Luis Alfonso de Carballo, em Cisne de Apolo (1602), faz referência interessante em relação ao decoro da nação a ser observado pelo artista:

[o decoro da nação se guarda] pintando as pessoas segundo o rito e trato de sua nação e terra, porque muito diferentes são os trajes, os adornos, tratos e comércios de uma nação a outra, e muito diferentes os costumes e ainda as condições. (...) E assim deve pintar o Poeta, guardando a cada nação seu decoro. ${ }^{3}$ (apud MARROQUIN, 2008, p. 146) 
Da mesma forma, o músico setecentista tinha que ter em conta o decoro de cada nação ao utilizar as escritas e os adornos. Como nos mostra a tratadística setecentista, ele devia conhecer as características de cada estilo nacional e as diferentes ocasiões, seja no tocar, no compor ou no ouvir.

Athanasius Kircher, em seu Musurgia Universalis (1662), aborda os aspectos técnico e nacional do estilo quando escreve que o stylus musicus é duplo, podendo ser impressus ou expressus. Segundo o autor, o estilo impressus é diverso segundo o temperamento de cada nação, ou a inclinação dos músicos de cada país; e o estilo expressus é baseado na razão e em um método de compor (KIRCHER, 2006. p. 33). Assim, a maneira de compor é particular em cada país, de acordo com o temperamento próprio do lugar, seguindo prescrições técnicas para uma maneira de compor.

O teórico e compositor Johann Mattheson também destaca as maneiras particulares da música nas diferentes nações:

Toda composição boa deve cumprir três requisitos, a saber: melodia (para a qual a invenção dá o início), harmonia e galanterie. A partir deste princípio, diferenciam-se os styli musicais, correntes nas mais importantes e reconhecidas [gemeldten] nações europeias (...). ${ }^{4}$ (MATTHESON, 2004, p. 202)

Ao escreverem sobre as características da música de cada nação, compositores e teóricos setecentistas fazem um julgamento comparativo levando em conta o próprio gosto e o gosto nacional. Mattheson, em seu Das Neu-Eröffnete Orchestre (1713) denomina o capítulo que trata das características da música de cada país como "Judicatória ou como se deve julgar a música”. Neste capítulo, ele faz uma análise das diferenças entre a música italiana, francesa, inglesa e alemã. Quantz, assim como Mattheson, discute este assunto dentro de um capítulo relacionado ao julgamento da música - "Como um músico e uma composição musical devem ser julgados”. Como vimos, o gosto está relacionado ao julgamento, à aprovação ou desaprovação da obra de arte. Quantz escreve que a diversidade do gosto é a maior responsável pelo julgamento das “diferentes Músicas”.

Segundo o autor,

a diversidade do gosto nas diferentes nações que ao menos tenham gosto pelas ciências, tem a maior influência sobre o julgamento musical e se manifesta muito mais no exame do acidental do que do essencial da música. Deste modo, é necessário investigar essa diversidade de gosto na música detalhadamente. ${ }^{5}$ (QUANTZ, 1983, p, 306)

\section{Os modelos italiano e francês}

Os gostos italiano e francês constituem os dois principais modelos mais discutidos e imitados por músicos e teóricos setecentistas. Quantz trata desses dois modelos opostos alinhado com as noções de gosto e imitação. Segundo o autor, uma vez que os gostos italiano e francês eram modelos aprovados e emulados, naturalmente se tornaram normativos e juízes do bom gosto para as demais nações.

Há dois povos em particular que têm alcançado estima considerável por sua melhoria do gosto musical, e que, conduzidos por suas inclinações naturais, têm percorrido caminhos diferentes para alcançar este fim. Estes dois povos são os italianos e os franceses. Outras nações têm aprovado o gosto desses dois povos, e procuram adotar e imitar o que lhes agradam mais em um ou em outro. Consequentemente, os dois povos 
têm se colocado como juízes soberanos do bom gosto na música; e como nenhum dos outros países tem sido capaz de contrapô-los, eles têm sido, em certo grau, os legisladores neste assunto por alguns séculos. A partir deles, o bom gosto tem sido transferido para os outros povos. ${ }^{6}$ (QUANTZ, 1983, p, 306)

Para Mattheson, a Itália representa a nação onde a música era mais cultivada, tendo sido imitada por todas as outras nações:

Devemos ter em mente que em nenhuma terra conhecida em todo o mundo, a música seja cultivada e estimada com tanta frequência, de tantas maneiras e modos e com tanto sucesso como na Itália. Certamente, é por isto que todas as outras nações que querem se distinguir na música emprestaram dela e a imitaram em todas as coisas. ${ }^{7}$ (MATTHESON, 2004, p. 205)

Segundo o autor, a música italiana é detentora dos maiores elogios, estando com ela o gosto e a aprovação da maioria. Ele chama a atenção para diversidade dos estilos nas diferentes regiões da Itália, em paralelo com os dialetos de uma língua única:

Os italianos, que hoje em dia parecem ganhar maior elogio, estando à frente de todas as outras nações pela beleza essencial de suas obras e também pelo entendimento artístico insinuante e sobrepujante nelas, e por ter o gout general na maior parte a seu lado, diferenciam-se não apenas do estilo dos franceses, alemães e ingleses, mas ainda, em certas peças, entre si. Por ex., um veneziano comporá diferente de um toscano, e este novamente diferente de um napolitano ou siciliano, etc. de modo que não haverá melhor comparação destas discrepâncias, do que [através de uma analogia] entre uma língua e seus dialetos. Estes diferenciam-se entre si, e podemos dizer que o genius musicus desta ou daquela província traz algo estrangeiro, mas no entanto, em princípio, [estes estilos] são todos frutos diversos de um galho único. ${ }^{8}$ (MATTHESON, 2004, p. 202-203)

Em seguida, Mattheson descreve as diferenças estilísticas próprias da música composta em Roma e em Veneza:

O estilo romano é mais grave que o veneziano; este [último] geralmente se concentra mais em uma melodia simples e fácil; aquele, contudo, em uma harmonia contínua; este penetra mais rapidamente no ouvido, agradando logo, do que aquele, que tem mais em si; neste, encontraremos algo mais galante, naquele, [algo] mais real. ${ }^{9}$ (MATTHESON, 2004, p. 203)

Mattheson dá continuidade à descrição dos subestilos da música italiana com os estilos napolitano e siciliano, ambos recebendo descrição similar. Aqui, o autor trata esses estilos como sendo uma música que segue o gosto do homem comum, sem o refinamento dos gostos veneziano e romano:

Os estilos napolitano e siciliano vem principalmente de uma arte de cantar muito particular e negligente. Suas espécies mais importantes são a giga inglesa lenta, ou o compasso composto, pois este contém uma tendresse não disfarçada, e o allegro, ou compasso alegre, que contenha um canto à la barquerole; nestas províncias o homem comum geralmente utiliza a guitarra para seu prazer, depende muito da aprovação do vulgo e por isto esta arte de compor fica atrelada ao gusto comum. ${ }^{10}$ (MATTHESON, 2004, p. 204)

Dentre os aspectos da música italiana que ajudaram a torná-la persuasiva, podemos destacar a adequação da língua italiana para a música, o que é notado através da cla- 
reza e riqueza dos sons das vogais e da nitidez das consoantes. Essas qualidades permitiam muitas nuances de intensidade e recitativos recheados de ornamentação melismática - bem apoiados por um baixo contínuo que devia apenas ajudar a transmitir os afetos do texto. A música instrumental herdou essas características com melodias atraentes, contornos bem definidos e a tradição do baixo contínuo, que permitia um desenvolvimento livre, florido e brilhante $^{11}$ da melodia. Segundo compositor e teórico musical Daniel Gottlieb Türk, as qualidades mais atraentes da melodia da música italiana são percebidas através da "flexibilidade cativante" da música instrumental e vocal, além da clareza e atratividade da melodia resultante de seu contorno e simetria (TÜRK, 1997, p. 404).

Ratner escreve:

Os italianos tinham habilidade especial para extrair figuras melódicas atraentes da harmonia. Nos allegros eles criaram frequentes padrões agradáveis bem ancorados de arpeggios para temas importantes, e figurações mecânicas em notas rápidas para passagens brilhantes. Nos adagios eles têm uma tradição de ornamentação florida - trillos, appoggiaturas, mordentes, tiratas - e arranjos em padrões irregulares. Essa ornamentação livre é sustentada por uma pontuação regular e um baixo estável que fixa o andamento. ${ }^{12}$ (RATNER, 1980, p, 338)

Como vimos, o estilo de compor determinado pelo gosto nacional segue um critério de adequação em relação a características perpetuadas por um país - e uma actoritas. Grassineau, em sua tradução do dicionário de Sebastien de Brossard (1708), escreve: "O estilo de Palestrina, Lully e Corelli; o estilo dos italianos, franceses e espanhois etc. (...) O estilo das composições italianas é pungente, florido, expressivo; o dos franceses, natural, fluente, delicado”. ${ }^{13}$ (GRASSINEAU, 1769, p. 242) É interessante notar o destaque de Lully e Corelli as duas auctoritates representantes dos dois principais estilos imitados pelos compositores setecentistas. Os dois compositores são mencionados frequentemente por Telemann e seus contemporâneos como os modelos da música francesa e italiana.

Arcangelo Corelli (1653-1713) é citado por diversos compositores alemães, como Muffat, Telemann, Mattheson e Quantz, como o grande modelo da música italiana. Richard Crocker (1986) escreve que Corelli foi muito ativo em Roma e aclamado como modelo perfeito da música instrumental em toda a Europa por várias gerações.

Apesar de todo sucesso de Corelli com a música instrumental, sua produção foi pequena, com apenas seis coleções publicadas: quatro de música de câmara para cordas, uma de sonatas para violino solo e uma de concertos para cordas. Cada uma dessas coleções contém doze composições, divididas em duas partes: da chiesa e da camera.

Crocker escreve sobre as sonatas de Corelli:

A música de Corelli é mais do que apenas mais fluente e clara do que aquela de seus predecessores [fluência harmônica e clareza temática]; em suas mãos delicadas a sonatas da chiesa se tornaram eloquentes com um lirismo antes encontrado apenas na música vocal. Este lirismo era a característica distintiva do estilo de Corelli, substituindo o virtuosismo e exuberância da primeira metade do século. ${ }^{14}$ (CROCKER, 1986, P. 304)

O autor cita também os concerti grossi como exemplo da inventividade inovadora do compositor: "Corelli deu pura expressão instrumental ao ripieno, prática habitual na performance das grandes obras sacras (vocais ou instrumentais) durante todo o século". ${ }^{15}$ (CROCKER, 1986, P. 304)

As Sonate a Violino e Violone o Cimbalo (opera quinta) de Corelli são um belo exemplo de como o compositor era considerado modelar na música instrumental italiana. Publi- 
cada em 1700 em Roma, essa série de sonatas foi reeditada inúmeras vezes durante a vida do compositor em diversos países da Europa. No decorrer de 11 anos a série foi reeditada em Roma (1700), Bologna (1700), Londres (1700, 1711), Amsterdam (1700, 1708, 1709, 1710) e Paris (1708). Apesar de todas as composições de Corelli terem sido populares na Europa, a opera quinta foi a obra que obteve maior sucesso, sendo utilizada como um método em diversos países. ${ }^{16}$

Assim, as sonatas de Corelli foram modelo deste gênero no séc. XVIII, imitadas desde sua disposição até o estilo de cada movimento que compõe a sonata. Vale lembrar que os adagios ornamentados pelo compositor representam importante registro da prática de ornamentação livre italiana, podendo ser aplicado a outras composições italianas que, em geral, não trazem as ornamentações escritas e devem ser improvisadas.

Em 1702 e 1707 surgiram também versões das sonatas três e quatro (sonate da chiesa) para flauta doce e baixo contínuo que tiveram os movimentos lentos ornamentados imitando o modelo de Corelli - a primeira versão atribuída a Schickhardt e a segunda a um "mestre eminente". ${ }^{17}$ Também a segunda parte da ópera quinta, das sonate da camera, recebeu versões para flauta doce e baixo contínuo, sendo publicada pelo famoso editor Walsh. Essa prática comprova a importância desta obra como um método que permitia a músicos de outras nacionalidades aprenderem a ornamentar e compor à maneira italiana, tendo Corelli como modelo de imitação.

Enquanto a auctoritas da música italiana era Corelli, Lully (1632-1687) era citado como o modelo para se compor à maneira francesa. A auctoritas francesa difere da italiana por ser representante de um estilo essencialmente teatral e por sua associação com Luis XIV, o Rei Sol. Quantz destaca que após 65 anos da morte de Lully, ele ainda era considerado a grande autoridade da música francesa:

Sabemos que os franceses enxergam Lully, um italiano, como um ditador musical; que seu gosto até hoje agrada em toda a França; e que eles se esforçam cuidadosamente para recuperar e manter seu modelo inalterado, se às vezes seus compatriotas tentam se desviar dele. ${ }^{18}$ (QUANTZ, 1983, p. 307)

Chartes Burney, em seu A general History of Music (1789), assim como Quantz, fala sobre a tendência conservadora da música francesa ao procurar se manter fiel ao estilo de Lully por quase um século:

Apesar das mudanças no sistema da ópera terem sido tão numerosas desde a morte do seu primeiro legislador, Lulli, a música [francesa] permaneceu estacionada por quase um século, contrariando as diversas tentativas que foram feitas no sentido de estimular atividades e iniciativas. ${ }^{19}$ (BURNEY, 1789, p. 608)

Giovanni Battista Lulli nasceu em Florença e chegou à França em 1646, com apenas quatorze anos, para servir à corte. Ele teve seus estudos musicais providos pela corte, tornando-se violinista virtuose e excelente dançarino, o que atraiu a atenção do rei. Logo ele dominou a música na corte de Luis XIV e se tornou o nome mais influente na história da música seiscentista francesa.

No reinado de Luis XIV, as artes foram utilizadas para construir a imagem pública real, o que elevou a cultura da corte a níveis antes nunca vistos. Luis XIV fez do ballet de cour o centro do entretenimento da corte. Lully foi nomeado compositeur de la musique instrumentale em 1653, começando assim a associação com o rei e se tornando seu confidente e ditador de todas as atividades musicais ${ }^{20}$ (BUELOW, 2004, p. 152). 
Lully desenvolveu a ouverture francesa, que foi imitada extensivamente por compositores alemães - e por Telemann. Ela era composta em duas partes, a primeira com caráter grave e figuras pontuadas, e a segunda com um estilo imitativo de caráter vivo. Ratner (1980) escreve que a ouverture era um gênero distinto de música cerimonial que, nas cortes e teatros franceses de Luis XIV, acompanhava a entrada dos espectadores reais, dos atores e dançarinos. Posteriormente, foi adotada em toda a Europa como peça de abertura para diversas performances teatrais, suítes instrumentais e algumas sinfonias.

Vale mencionar que a despeito de toda fama da música italiana, muitos compositores alemães, em especial Telemann, eram defensores do estilo francês e tornaram as ouvertures muito populares na Alemanha. Mattheson escreve sobre a incapacidade dos italianos em compor uma ouverture, a despeito de toda qualidade de sua música, fazendo todo um elogio à beleza da ouverture francesa e mostrando a grande admiração dos alemães pelo gênero:

Deixemos, no entanto, os italianos ostentarem e se vangloriarem o quanto quiserem a respeito de suas vozes e de suas artes. Em vão será pedido a eles que componham uma abertura francesa como se deve. Isto basta para dizer que geralmente, a música instrumental dos franceses se destaca sobremaneira. Apesar de os italianos se empenharem muito nas suas sinfonias e concertos, que certamente são especialmente bonitos, uma ouverture francesa viva é preferível a estes. Pois, ao lado da composição de uma pieçe destas com sua suite à la françoise, sua execução no seu gênero, feita pelos próprios franceses, é tão admirable, tão unie e tão ferme, que nada pode sobrepô-la. ${ }^{21}$ (MATTHESON, 1713, p. 225-226)

É interessante observar que a tradição de uma orquestra disciplinada surgiu na França e foi estabelecia por Lully. Essa grande disciplina da orquestra francesa em relação à italiana se deve à importância da dança na música francesa, como escreve Ratner:

Graças ao ballet, a orquestra francesa no séc. XVII e XVIII teve maior destaque do que a orquestra italiana. A textura obrigatória das cordas francesas em cinco partes criou um som maciço e mais denso. [...] o grave ou adagio cheio e majestoso, que inicia a ouverture, chamava a atenção para a importância da ocasião. [...] Assim, a tradição de uma orquestra importante surgiu na França e foi firmemente estabelecida por Lully, tanto no diz respeito ao escopo quanto à disciplina. ${ }^{22}$ (RATNER, 1980, p. 350)

Na orquestra de Lully (os 24 Violons du Roi), somente as partes superiores eram tocadas pelos violinos. As três partes intermediárias eram tocadas por instrumentos similares à viola, mas de tamanhos variados (progressivamente maiores): haute contre, taille e quinte, que eram todos instrumentos da braccio e não gambas (basse de viole). A quinta parte era executada pelos basse de violon, maiores que os cellos. Os sopros, dobrando sempre as partes I e II, conferiam uma sonoridade especial à orquestra francesa.

O modelo francês foi muito estudado por compositores germânicos (as danças, a ouverture e o modelo de orquestra) ${ }^{23}$, que foram além: a organização de corte, as maneiras do cortesão e o idioma eram bastante emulados pelos alemães - influenciados pela grande força de Versalhes (REIPSCH, 2009, 7).

Mattheson, apesar de reconhecer as qualidades da música francesa, ressalta que esta não era tão apreciada e aprovada pelo gosto dos estrangeiros quanto sua língua:

Não negamos que tanto a composição quanto a execução francesa a seu modo merece seu próprio louvor e possivelmente não deixa nada a desejar aos italianos. Mas a maior parte nestes assuntos depende do gout, e os franceses ainda não obtiveram uma aprovação geral de sua música, como [a aprovação] conquistada por sua língua, e seu elogio possivelmente só se espalha dentro, mas não muito além dos limites da França. ${ }^{24}$ (MATTHESON, 1713, p. 207) 
Entretanto, Mattheson destaca que os franceses eram imitados em sua música de dança, situando a música francesa ao lado da música italiana como modelo de imitação:

Mas é preciso conceder que na música instrumental, em especial na música choraica ou de dança, os franceses são mestres e são imitados em todos os lugares, sem serem imitados [copiados]. Quando, portanto, comparamos a música francesa com a italiana, não seria incorreto dizer que ambas as músicas, a italiana e a francesa, parecem ter algo próprio e original; enquanto as outras geralmente se referem a uma ou a outra, e fazem uma imitação ou uma mistura destas. ${ }^{25}$ (MATTHESON, 1713, p. 208)

A especialidade francesa em danças foi desenvolvida através de séculos de prática e refinamento no teatro, nas cortes e salões de Versalhes e Paris, sendo a maioria das danças correntes no séc. XVIII de origem francesa. Ainda, por meio das danças francesas, a forma de reprise dupla foi padronizada.

Ratner (1980) faz uma comparação entre a tendência vocal e a importância da melodia na música italiana em oposição à declamação e à dança na música francesa. A primeira, largamente difundida internacionalmente e a segunda, mais restrita às cortes francesas:

A atividade musical francesa estava centralizada em Paris e Versalhes, enquanto a musica italiana era exportada em todo o mundo ocidental. O teatro era o centro da vida artística francesa; a música era complementar à declamação e à dança, enfatizando o efeito da palavra e completando o sentido do movimento na coreografia, em contraste à ênfase na melodia e à excelência vocal italiana. ${ }^{26}$ (RATNER, 1980, p. 345)

Entretanto, se a música francesa não foi tão exportada quanto a italiana, o mesmo não se podia dizer quanto à sua dança:

Enquanto a maneira de cantar francesa estava confinada principalmente aos salões e teatros franceses, as danças francesas eram exportadas constantemente durante o séc. XVIII; dançarinos e mestres de dança franceses viajaram por toda a Europa da mesma maneira que os compositores e instrumentistas italianos. ${ }^{27}$ (RATNER, 1980, p. 348)

\section{A rivalidade dos dois estilos}

Durante os séc. XVII e XVIII, as músicas francesa e italiana foram alvos de diversas discussões que rivalizavam as características desses dois estilos opostos. Essas discussões, principalmente francesas, circularam na Inglaterra e Alemanha e são bastante interessantes por trazerem à tona as qualidades e defeitos de cada estilo segundo a visão de músicos e teóricos da época. Olivier Strunk (1998) escreve que as músicas italiana e francesa se desenvolveram entre linhas separadas no séc. XVII. Entretanto, muitos franceses que visitaram a Itália se tornaram fortes partidários da música italiana, especialmente da música teatral. O padre, físico e historiador Fraçois Raguenet, que protagonizou um famoso debate sobre os dois estilos, ouviu as óperas de Lully cantadas em Paris e, em Roma, as obras de Corelli e Giovanni Bononcini.

Na comparação das músicas francesa e italiana de autoria de Raguenet (Paralele des italiens et des François, em ce qui regarde la musique et les opéra, 1702), ele elogia o desenho poético, lirismo, trajes, dança e função do baixo da música teatral de Lully, mas critica a palidez dessa música ao compará-la com o som da orquestra romana e com as habilidades vocais dos castrati. Raguenet estava disposto a abrir mão do refinamento na poesia, enredo, 
dramaturgia e som instrumental da música francesa, em troca dos vívidos recursos musicais para transmitir emoções dos italianos (apud STRUNK, 1998. p. 674).

Raguenet (1702), conforme citado por Strunk (1998, p. 674), compara os dois estilos, ressaltando a adequabilidade da língua italiana à música vocal: "a língua italiana é muito mais naturalmente adaptada à musica do que a nossa; suas vogais são todas sonoras, ao passo que mais da metade das nossas são mudas (...)”. ${ }^{28}$

Vale lembrar que o italiano era considerado "a língua da ópera”, exceto em teatros parisienses, onde a música vocal era mais silábica e menos ornamentada.

Ratner escreve:

Os italianos consideravam a voz como o mais belo, mais perfeito instrumento musical, um modelo para todos os outros instrumentos, e eles escreviam sua música para exibir a voz em toda sua riqueza, sonoridade, brilho e flexibilidade (...). A França, por outro lado, utilizava a voz como um veículo para declamar um texto elegante, cheio de conteúdo; a música era utilizada para enfatizar as nuances expressivas das palavras. ${ }^{29}$ (RATNER, 1980, p. 345)

O texto de Raguenet teve alguma aceitação na França, embora tenha provocado os defensores da música francesa. Podemos citar Jean Laurent Le Cerf de la Viéville, cuja contra-comparação dos dois estilos motivou Raguenet a publicar uma Défense (1705) do seu próprio paralelo. A polêmica permaneceu viva em reimpressões e traduções até 1759 e chegou a ser conhecida em outros países da Europa. Burney, para quem Raguenet era "um homem de gosto e inteligência", ainda cita o texto de Raguenet em sua A general History of Music (BURNEY, 1789, p. 608).

Mattheson também menciona a polêmica entre os dois autores em seu das Neu-Eröffnete Orchestre (1713): "Um francês de nome le Sieur de Viéville parece ter escrito uma resposta ao Abbé Raguenet, denominada Comparaison de la Musique Francoise \& Italienne; contudo, ainda não tive oportunidade de conferi-la” ${ }^{30}$ (MATTHESON, 2004, p. 231).

No decorrer do séc. XVIII outros autores, como Türk, Carl Philipp Emanuel Bach, Mattheson e Quantz deram continuidade às críticas e comparações dos estilos italiano e francês. Türk, citando Rousseau (que tinha preferência pelo estilo italiano), escreve: "O estilo francês seria, de acordo com Rousseau, insípido, plano, duro, de articulação pobre e monótona" ${ }^{31}$ (TÜRK, 1997, p. 404).

Entretanto, apesar de não demostrar admiração pelo estilo francês, o autor reconhecia suas qualidades na música para teclado:

Apesar dos franceses escreverem de uma maneira seca e vazia, ou de negligenciarem um pouco a harmonia, deve-se dar mais crédito ao seu gosto. Não há dúvidas que, entretanto, eles têm tido por muito tempo uma posição eminente como compositores de teclado e nesse aspecto merecem muito mais preferência do que os italianos. ${ }^{32}$ (TÜRK, 1997, p. 404)

C. P. E. Bach, em seu Versuch über die wahre Art das Clavier zu spielen, ao fazer uma crítica ao fato de os alunos estarem sendo pouco estimulados a tocarem peças que não fossem suas próprias composições, fala das características das peças francesas para teclado: "sempre foram ótimas escolas para tecladistas, uma vez que a França se distingue de outros países pela maneira coerente e correta de tocar. Todos os ornamentos necessários são indicados claramente" (BACH, 2009, p. 22).

Mais adiante, ele faz uma crítica ao excesso de agréments dos compositores franceses, afirmando que os alemães foram mais eficazes nesse ponto: 
Deve-se fazer justiça aos franceses, por serem particularmente meticulosos na notação de suas peças. Os maiores mestres do nosso instrumento na Alemanha agiram da mesma forma, contudo, sem excesso de ornamentos, como os franceses. E quem sabe se não foi a partir dessa escolha inteligente e da quantidade moderada de ornamentos dos alemães, que os franceses, atualmente, não mais sobrecarregam quase toda nota com um ornamento, o que obscurecia a necessária clareza e a nobre simplicidade do canto. (BACH, 2009, p. 69)

A música italiana, apesar de muito elogiada, foi bastante debatida e também recebeu críticas, como seu excesso de liberdade, mudanças de tonalidades muito frequentes e constantes repetições de uma mesma passagem.

Türk escreve:

O estilo italiano é agradável, cantante, cheio (frequentemente exagerado), brilhante, variado e expressivo. Assim costumamos caracterizá-lo. Atualmente, contudo, encontramos também muitas [coisas] sem sentido, "batidas" (demasiadamente ouvidas), insignificantes, superficiais, etc. nas obras de diversos compositores italianos. Mas devemos dar à maioria deles o crédito por seu canto ter uma certa flexibilidade cativante. ${ }^{33}$ (TÜRK, 1997, p. 404)

Em sentido contrário, a música francesa era conhecida por seu excesso de regras e disciplina, o que era elogiado por alguns e criticado por outros. Raguenet (1702) escreve sobre a rigidez das regras da música francesa em oposição à liberdade da música italiana:

Os franceses se consideram arruinados se eles violam minimamente as regras; eles encantam, agradam, cortejam o ouvido e ainda assim são receosos do sucesso, apesar de tudo ser feito com uma ordem exata. O italiano, mais ousado, altera o tom e o modo sem nenhum temor ou hesitação; ele faz cadências duplas ou triplas de sete ou oito compassos juntos, em tonalidades que nós acharíamos incapazes de uma mínima divisão. [...] Os italianos se aventuram em tudo o que é ousado e fora da regra, mas eles o fazem como quem tem o direito de ousar e está certo do sucesso. ${ }^{34}$ (apud STRUNK, 1998, p. 675)

Mattheson também chama a atenção para a disciplina dos instrumentistas franceses em relação aos italianos e aos alemães:

Eles [franceses] aprendem com antecedência, praticamente de cor, e não se envergonham, como fazem os alemães, de ensaiá-la e repeti-la centenas de vezes, para que [a execução] saia acurada. [...] No entanto, encontramos, pelo contrário, poucos franceses que consigam, como um alemão ou um italiano treinado, ler algo à primeira vista. ${ }^{35}$ (MATTHESON, 2004, p. 226)

\section{Considerações finais}

Através das discussões setecentistas sobre a maneira de compor e tocar dos italianos e franceses, podemos observar que, apesar de modelares, ambas eram alvo de críticas. A música francesa era criticada em relação à sua melodia (com termos como "insípido, pálido, plano, duro, seco e vazio”), à articulação (“pobre e monótona”) e em relação à harmonia ("negligente"). Entretanto, a música de teclado, de dança e a ouverture eram cultivadas e serviam de modelo. A música francesa era elogiada pela sua clareza de notação, mas criticada por seu excesso de agréments. Ainda, a disciplina da orquestra francesa era bastante comentada e respeitada. 
A música italiana, por sua vez, era modelo na maneira de tratamento da melodia (brilho, simetria e liberdade) e possuía características advindas da música vocal, como lirismo, flexibilidade, expressividade e clareza da textura e das melodias. Porém, recebia críticas por seu excesso de liberdade e superficialidade. Enquanto a música francesa era imitada na sua música de dança, o estilo italiano era referência na música vocal. Os instrumentistas franceses eram elogiados pela maneira correta e ensaiada de tocar, porém, quando comparados aos italianos, ficavam atrás na capacidade de improvisar e ler à primeira vista.

Todas essas particularidades foram muito estudadas, debatidas e experimentadas pelos compositores alemães. Vale mencionar que a Alemanha não era uma nação unificada, sua realidade era de uma nação fragmentada constituída por centenas de principados independentes. A desunião dos estados germânicos, resultado de uma história marcada por conflitos, é um dos fatores que tornou a música alemã suscetível às influências musicais estrangeiras. Assim, as cortes germânicas, comparadas com outras cortes europeias, eram excepcionais em sua natureza cosmopolita, sendo dominadas pelos gostos italiano e francês (PAOLIELLO, 2011, 89).

Deste modo, compositores alemães conviveram com músicos italianos e franceses, absorvendo os estilos estrangeiros através desse contato e do estudo aprofundado desses modelos - tanto em razão de um gosto pessoal quanto para suprir uma demanda da corte à qual serviam. Deste modo, os textos alemães que tratam dos estilos de compor e tocar italiano e francês, críticos ou elogiosos, representam um importante testemunho dessas músicas nacionais modelares da época.

Como vimos, teóricos e compositores setecentistas se dedicavam à formação do bom gosto, que se dava através do aperfeiçoamento da razão e do discernimento. Mesmo nos tratados denominados de música prática, vemos que a maior parte de seu conteúdo diz respeito à formação do gosto através do estudo de temas amplos e complexos que vão desde os preceitos da retórica clássica (emulada por compositores setecentistas e aplicada à composição do discurso musical), ${ }^{36}$ até o estudo detalhado dos afetos e dos diferentes gêneros e estilos musicais. Nesses tratados, vemos que somente através do estudo e aperfeiçoamento do bom gosto é possível apreciar, julgar e tocar de maneira adequada.

\section{Notas}

1 Versuch einer Anweisung die Flöte Traversière zu spielen; mit verschiedenen, zur Beförderung des guten Geschmackes in der praktischen Musik dienlichen Anmerkungen begleitet, und mit Exempeln erläutert (QUANTZ, 1983, сара).

2 Tradução nossa. No original: "Die Composition, und die Ausführung einer Musik im Ganzen richtig zu beurtheilen (...) wird nicht nur erfordert, da $\beta$ man einen vollkommen guten Geschmack besiße, und die Regeln der Seßkunst verstehe: sondern man muß auch von der Art und Eigenschaft eines jeden Stückes, es sey im Geschmacke dieser oder jener Nation, zu dieser oder jener Absicht verfertiget, eine hinlängliche Einsicht haben; damit man nicht eine Sache mit der andern verwirre" (QUANTZ, 1983, p. 287).

3 Tradução nossa. No original: "Pintando las personas según el rito y trato de su nación y tierra, porque muy diferentes son los trajes, los adornos y tratos y comércios de uma nación a outra, y muy diferentes las costumbres y aun las condiciones. (...) Y ansí se dbe pintar del Poeta para guardar a cada nación su decoro" (MARROQUIN, 2008. p. 146).

4 Tradução nossa. No original: “(...) eine jede Composition, die gut seyn soll / 3. Requisita, nemlich die Melodie, (wozu die Invention den Anfang machet) die Harmonie, und die Galanterie haben muesse / so wollen wie nach diesem Principio den Unterscheid des musicalischen Styli, welcher bey den gemeldten vornehmsten Europaeischen Nationen im Schwange gehet (...)” (MATTHESON, 2004, p. 202).

5 Tradução nossa. No original: "Der Unterschied des Geschmackes, der sich bey verschiedenen Nationen, welche and den Wissenschaften überhaupt Geschmack finden, nicht sowohl in Ansehung des Wesentlichen, als vielmehr des Zufälligen der Musik, äußert, hat in die musikalische Beurtheilung den größten Einfluß. Es ist also nöthig, diesen Unterschied des Geschmackes, in der Musik, noch etwas weitläufiger zu untersuchen" (QUANTZ, 1983, p. 306). 
${ }^{6}$ Tradução nossa. No original: "Zwei Völker in den neuern Zeiten aber, haben sich besonders, nicht nur um die Ausbesserung des musikalischen Geschmackes verdient gemacht, sondern auch darinne, nach Anleitung ihrer angebohrnen Gemüthtsneigungen, vorzüglich von einander unterschieden. Dieses sind die Italiäner, und die Franzosen. Andere Nationen haben dem Geschmacke dieser beyden Völker den meisten Beyfall gegeben, und entweder diesem, oder jenem nachzufolgen, und etwas davon anzunehmen, gesuchet. Hierdurch sind die gedachten beyden Völker auch verleitet worden, sich gleichsam zu eigenmächtigen Richtern des guten Geschmackes in der Musik aufzuwerfen: und weil niemand von den Ausländern lange Zeit nichts dawider einzuwenden gehabt hat; so sind sie gewissermaßen, einige Jahrhunderte hindurch, wirklich die musikalischen Geseßgeber gewesen. Von ihnen ist hernach der gute Geschmack in der Musik auf andere Völker gebracht worden” (QUANTZ, 1983, p. 306).

7 Tradução nossa. No original: "Woraus aus denn erhellet / daß in keinen noch bekanten Lande in der ganzen Welt / die Music so haeufig / auf so mancherley Art und Weise / und mit solchem Succes als in Italien excoliret und aestimiret werde. Es ist dieses so gewi / da $\beta$ auch alle uebrige Nationes, die sich in der Music jemahls haben distinguiren wollen / den Italiaenern fast alles abgeborger / und sie schier in allen Stuecken nachgeaeffet haben" (MATTHESON, 2004, p. 205).

${ }^{8}$ Tradução nossa. No original: "Die Italiaener / welche heutiges Tages / theils durch die wesentliche Schoenheit ihrer Wercke / theils auch durch die uebertruenchte und insinuante Kunst-Griffe in der Composition, den Prei $\beta$ vor allen andern Nationen davon zu tragen scheinen / und den generalen Gout mehrentheils auff ihrer Seiten haben / sind nicht nur in ihrem Stylo von den Franzosen / Deutschen und Engellaendern; sondern in gewissen Stuecken unter sich selbst mercklich unterschieden. Z. E. Ein Venetianer, wird anders setzen / als ein Toscaner, dieser wieder anders als ein Neapolitaner oder Sicilianer \&c. also da $\beta$ ich keine bessere Vergleichung dieser Discrepanz wueste / als etwan mit den Dialectis ihrer Sprache; denn wie selbige von einander differiren / so koente man auch sagen / da $\beta$ der Genius Musicus in dieser oder jener Province etwas frembdes hervor bringe / ob gleich im Grunde alles einen Stamm / aber diverse Fruechte hat” (MATTHESON, 2004, p. 202-203).

9 Tradução nossa. No original: "Der Romanische Stylus wird wol gravitaetischer seyn als der Venetianische; dieser wird gemeiniglich mehr auf eine blosse leichte Melodie; jener aber mehr auf eine durchgehende Hamonie reflectiren; dieser wird ehender ins Gehoer dringen / und nicht so langsam gefallen / als jener/der etwas mehr auf sich hat; diesem wird man galantes, bey jenem mehr reelles finden” (MATTHESON, 2004, p. 203).

10 Tradução nossa. No original: "Der Neapolitanische und Sicilianische Stylus kommt hauptsaechlich auf eine ganz particuliere und negligente Art zu singen an. Ihre vornehmste Species ist entweder ein langsamer Englischer Giquen oder ein schlechter Tact, da eine ungeschmickte Tendresse statt hat; die andere Species aber/vom Allegro oder lustigen Tact, enthaelt meistentheils einen Gesang, à la barquerole / denn weil sich in diesen Laendern der gemeine Mann beym Singen meistens der Guitarre zu seiner Ergetzung bedienet / und weil zugleich daselbst von der Approbation des Vulgi viel dependiret / so bleibet auch immer bey derselben Art zu componieren von dem gemeinen Gusto etwas kleben” (MATTHESON, 2004, p. 204).

11 Estilo Brilhante: termo usado por Daube (1797), Türk (1789), Koch (1802) para passagens rápidas que mostravam virtuosismo ou sentimentos intensos (RATNER, 1980, p. 19).

12 Tradução nossa. No original: "Italians had a special knack for drawing attractive melodic figures from the harmony. In their allegros they created well-anchored, pleasing patterns often in arpeggios for salient themes, and exuberant mechanical figurations in rapid notes for brilliant passage work (...). In their adagios they had a tradition of florid ornamentation - trills, appoggiaturas, mordents, tiratas - arranged in irregular patterns. This free floridity is underpinned by regularity of punctuation and a steady bass that fixes the pace" (RATNER, 1980, p. 338).

13 Tradução nossa. No original: “The style of palestrina, of Lully, and of corelli; the style of italians, French, Spaniards, \&c. (...) the Style of the Italian compositions is poignant, florid, expressive; that of the Frech, natural, flowing, tender \&c” (GRASSINEAU, 1769, p. 242).

14 Tradução nossa. No original: "Corelli’s music is more than just smoother and clearer than that of his predecessors; in his sensitive hands the church sonata became eloquent with a lyricism found before only in vocal music. This lyricism was the distinguishing feature of Corelli's style, replacing the virtuoso brilliance and whimsy of the first part of the century" (CROCKER, 1986, p. 304).

15 Tradução nossa. No original: “(...) Corelli gave purely instrumental expression to the ripieno practice customary in the performance of larger sacred works (vocal or instrumental) throughout the century” (CROCKER, 1986, p. 304).

${ }^{16}$ Cf.: Arcangelo Corelli. Twelve Violin Sonatas, op. V. Urtex Edition [Prefacio de F. Chrysander, 1890].

17 Cf.: Arcangelo Corelli. Sonata in F Major opus 5, no. 4 for treble recorder and basso continuo. Musica Rara [Prefacio de John Madden, 1976].

18 Tradução nossa. No original: "Man weis, das Lülly, welchen die Franzosen fast als einen musikalischen Befehlshaber ansehen, und seinem Geschmacke noch bis ißo durch ganz Frankreich Beyfall geben, ja denselben, wenn etwan einige ihrer Landsleute davon abgehen wollen, sorgfältig wieder herzustellen, und ungeändert im Schwange zu erhalten bemühet sind, ein Welscher gewesen ist” (QUANTZ, 1983, p. 307).

19 Tradução nossa. No original: "But though the revolutions in opera government have been so numerous since the death of its first legislator, Lulli, Music remained stationery for near a century, in spite of the several attempts that were made in order to stimulate activity and enterprize” (BURNEY, 1789, p. 608).

${ }^{20}$ Buelow destaca que, a princípio, o estilo de Lully era essencialmente italiano e que gradualmente ele foi abandonando as características italianas e formulando o que seria conhecida como a música francesa. Cf.: BUELOW, Georg J. A History of Baroque Music. Bloomington: Indiana University Press, 2004. 
21 Tradução nossa. No original: "Es möge nun aber die Italiäner mit ihren Stimmen und Künste prahlen und prangen wie sie immer wollen / Trotz sey ihnen geboten / da $\beta$ sie mir eine rechte Französiche Ouverture machen / oder auch einmahl / wie sichs gebühret herausbringen solten. $\mathrm{Da} \beta$ wil so viel sagen / da $\beta$ generalment die Instrumental-Music der Franzosen recht was sonderlichs voraushabe. Ob sich auch gleich die Italiäner die gröste Mühe von der Welt mit ihren Symphonien und Concerten geben / welche auch gewi $\beta$ überaus schön find / so ist doch wol eine frische Französische Ouverture ihnen allen zu praeferiren. Denn / nechst der Composition einer solchen Pieçe mit ihrer Suite à la Françoise, ist die Excecution in ihrem Genere, welche die Franzosen derselbigen geben / so admirable, so unie und so ferme, daß nichts darüber seyn kan” (MATTHESON, 2004, p. 225-226).

${ }^{22}$ Tradução nossa. No original: Thanks to ballet, the French orchestra in the 17th and 18th centuries enjoyed greater prominence in the theater than the Italian orchestra did. The obligatory five-part French string texture created a massive sound and a heavier (...). the full, stately grave or adagio that began the overture called attention to the importance of the occasion (...). Thus the tradition of an important orchestra arose in France and was firmly established by Lully, both with respect to scope and discipline” (RATNER, 1980, p. 350).

${ }^{23}$ Vale lembrar, que a principal fonte de informação de que dispomos atualmente sobre a prática orquestral francesa é o Floriregium Musicum (1687), do compositor austríaco Georg Muffat.

${ }^{24}$ Tradução nossa. No original: "Man streitet hierbey nicht / daß nicht so wol die Französische Composition als Excecution, in ihrer Art / ihr eigenes Lob verdiene / und vielleicht der Italiänischen nicht viel nachgiebet; allein weil ein grosses Theil in solchen Sachen von dem Gout dependiret / und aber die Franzosen noch keine solche generale Approbation ihrer Music, als wol ihrer Sprache / in der Welt erhalten haben / so wird sich vermuhtlich das davon etwa zu machende Elogium hauptsächlich intra, und nicht gar weit extra fines Galliae erstrecken können” (MATTHESON, 2004, p. 207).

25 Tradução nossa. No original: "So viel muß man gerne gestehen: In der Instrumental, insonderheit aber in der Choraischen oder Tantz-Music sind die Franzosen Meister / und werden überall / ohne imitiret zu werden / imitiret. Wenn man dannenhero Musicam Gallicam, respectu Italicae, alternam ab illâ nennen wolte / würde es eben kein gro $\beta$ Unrecht seyn / weil doch diese beyde / die Italiänische und Französiche Music nemlich / alleine etwas eigenes und originelles an sich zu haben scheinen; dahingegen andere sich gemeiniglich gerne auf eine oder alle beyde beziehen / und entweder eine Nachahmung oder Vermischung machen” (MATTHESON, 2004, p. 208).

${ }^{26}$ Tradução nossa. No original: "French musical activity was centered principally in Paris and Versailles, hereas Italian music was exported throughout the western world. The theater was the center of French artistic life; music was an adjunct to declamation and dancing, heightening the effect of the word and completing the sense of movement in choreography, in contrast to the Italian emphasis upon melody and excellence in vocalism" (RATNER, 1980, p. 345).

27 Tradução nossa. No original: "While the French style of singing was confined principally to French theaters and salons, French dances were exported constantly throughout the 18th century; French dancers and dancing masters traveled through Europe much in the way Italian composers and performers did” (RATNER, 1980, p. 348).

${ }^{28}$ Tradução nossa. No original: "The Italian language is much more naturally adapted to musick than ours; their vowels are all sonorous, whereas above half of ours are mute (...)”. Cf.: Paralele des italiens et des François, em ce qui regarde la musique et les opéra (Paris, 1702) In: STRUNK, 1998, p. 674.

${ }^{29}$ Tradução nossa. No original: “The Italians regarded the voice as the most perfect musical instrument, a model for all other instruments, and they wrote their music to display the voice in all its richness, sonority, brilliance, and flexibility (...). The French, on the other hand, took the voice to be a vehicle for declaiming an elegant text, full of content; music was used to heighten the expressive nuances of the words" (RATNER, 1980, p. 345).

${ }^{30}$ Tradução nossa. No original: "Ein Franzose / Nahmens le Sieur de Vieuville soll zwar an de Abbé Raguenet Antworten geschrieben haben / so er nennet: Comparaison de la Musique Françoise \& Italienne; alleine ich habe biß dato noch nichts davon auffstäubern können.” In: MATTHESON, Johann (1713). Op. cit., III, 1, 18, p. 231.

31 Tradução nossa. No original: "Der französiche Styl soll, nach Rousseaus Urtheil, fade, platt oder hart, schlecht abgetheilt und monotonisch seyn” (TÜRK, 1997, p. 404).

${ }^{32}$ Tradução nossa. No original: "Denn außer da $\beta$ die französischen Komponisten wohl zuweilen etwas leer und trocken schreiben, oder auch den harmonischen Theil ein wenig vernachlässigen, mu $\beta$ man dennoch ihrem Geschmacke gegenwärtig mehr Gerechtigkeit wiederfahren lassen. Da $\beta$ sie aber unter den Tonsetzern für das Klavier schon längst einen ansehnlichen Rang behauptet haben, und in dieser Rücksicht den italiänischen Komponisten weit vorgezogen zu werden verdienen, ist außer allen Zweifel” (TÜRK, 1997, p. 404).

33 Tradução nossa. No original: "Der italiänische Styl ist gefällig, singend, voll, (oft überladen,) glänzend, mannigfaltig und ausdrucksvoll. So charakterisirte man ihn wenigstens ehedem. Gegenwärtig trifft man freylich auch viel Zweckloses, oft Gehörtes, Unbedeutendes, Seichtes u.dgl. in den Werken verschiedener italiänischen Tonsetzer an; doch mu $\beta$ man ihnen größentheils das Verdienst zugestehen, da $\beta$ ihr Gesang eine gewisse (einnehmende) Geschmeidigkeit hat” (TÜRK, 1997, p. 404).

${ }^{34}$ Tradução nossa. No original: "The French would think themselves undone, if they offended in the least against the rules; they flatter, tickle, and court the ear, and are still doubtful of success, tho' ev'ry thing be done with an exact regularity. The more daring Italian changes the tone and the mode without any awe or hesitation; he makes double or treble cadences of seven or eight bars together, upon tones we should think incapable of the least division. (...) The Italians venture at ev'ry thing that is harsh, and out of the way, but then they do it like people that have a right to venture, and are sure of success" (STRUNK, 1998, p. 675). 
${ }^{35}$ Tradução nossa. No original: "Sie lernen es aber vorhero fast ganz auswendig / und schämen sich gar nicht / wie die Teutschen thun / ein Ding wol hundertmahl zu probieren und zu repetiren / damit es ja fein accurat gehe (...) Indessen findet man auch im Gegentheil wenig Franzosen / die ein Ding ex tempore, so wie ein Sattel-sester Teutscher / oder geübter Itanianer / treffen" (MATTHESON, 2004, p. 226).

${ }^{36}$ Sobre a emulação das retóricas clássicas pelas poéticas musicais setecentistas, cf: (LUCAS, 2005, 2006, 2008 e BARROS, 2006).

\section{Referências}

BACH, Carl Philipp Emanuel. Ensaio sobre a maneira correta de tocar teclado. Campinas: Ed. Unicamp, 2009.

BARROS, Cassiano de Almeida. A orientação retórica no processo de composição do Classicismo observada a partir do tratado Versuch einer Znleitung zur Composition (1782-1793) de H. C. Koch. Dissertação de mestrado, Universidade Estadual de Campinas, 2006.

BUELOW, Georg J. A History of Baroque Music. Bloomington: Indiana University, 2004.

BURNEY, Charles. A general History of Music. Londres: 1789. (fac simile). Disponivel em: <http://books.google.com/books?id=MCAAAAcAAJ\&printsec $=$ frontcover\&dq=burney\&ei=L8BFT qCOBNGYUKuQjNwF\&cd=3\#v=onepage\&q\&f=false>. Acesso em: 07 mar 2009.

CROCKER, Richard L. A history of musical style. New York: Dover, 1986.

ECO, Umberto. Arte e Beleza na Estética Medieval. Rio de Janeiro: Record, 2010.

GRASSINEAU. Musical Dictionary. Londres: 1769 (fac simile). Disponivel em: <http://books. google.com>. Acesso em: 07 mar 2009.

KIRCHER, Athanasius. Musurgia Universalis (1662). Kassel: Bärenreiter, 2006.

LUCAS, Mônica Isabel. Humor e Agudeza em Joseph Haydn: quarteto de cordas Op. 33. São Paulo: Annablume; Fapesp, 2008.

. Humor e Agudeza nos Quartetos de Cordas op. 33 de Joseph Haydn. Tese de doutorado, Universidade Estadual de Campinas, 2005.

. Conhecedores e Amadores na Crítica Setecentista à Música de Haydn. Revista Opus, n. 12, 2006.

. Imitação e Linguagem na Música Setecentista. Pós-doutorado, FFLCH-USP, 2008.

MARROQUIN, Lucia Dias. La Retorica de los Afectos. Kassel: Reichenberger, 2008.

MATTHESON, Johann. Das Neu-Eröffnete Orchestre (1713). Laaber: Laaber, 2004.

PAOLIELLO, Noara. Os Concertouvertures de Georg Philipp Telemann: um estudo dos Gostos Reunidos segundo as preceptivas setecentistas de Estilo e Gosto. São Paulo: Dissertação de Mestrado - Escola de Comunicação e Artes/ Universidade de São Paulo, 2011.

. Acepções de Gosto na Música Setecentista: uma contribuição para a definição do termo gosto na música. Anais do XXI Congresso da ANPPOM, Uberlândia, 2011.

QUANTZ, Johann Joachim. Versuch einer Anweisung die Flöte Traversière zu spielen (1752) Leipzig: Deutscher Verlag für Musik, 1983.

RATNER, Leonard. Classic Music: expression, form and style. New York: Schirmer, 1980. 
REIPSCH, Ralph-Jürgen. Telemann und Frankreich: Frankreich und Telemann. Magdeburg: Olms, 2009.

STRUNK, Olivier. Source Readings in Music History. New York: Norton, 1998.

TÜRK, Daniel Gottlob. Clavierschule oder Anweisung zum Clavierspielen für Lehrer und Lernender (1789). Kassel: Bärenreiter, 1997.

Noara Paoliello - Mestre e doutora pela Universidade de São Paulo (CMU-ECA/USP) com auxílio financeiro da FAPESP, sob orientação de Mônica Lucas. Realizou estágio doutoral de 1 ano, com apoio financeiro da FAPESP, na Martin Luther Universität (Halle, Alemanha) sob orientação de Wolfgang Hirschmann, onde visitou também os arquivos do Telemann-Zentrum (Magdeburg). É licenciada em música pela Universidade Federal do Estado do Rio de Janeiro (UNIRIO) sob orientação de Helder Parente. Como flautista, se dedica à interpretação da música historicamente orientada dos sécs. XVI, XVII e XVIII, tendo se apresentado como solista e camerista no Rio de Janeiro e em São Paulo. 